\title{
Editorial - Is ISO 55000:2014 the new dawn in asset management?
}

\section{Krisen Moodley}

Senior Lecturer, School of Civil Engineering, University of Leeds, Leeds, UK

Infrastructure asset management has reached an important juncture in its development with the publication of ISO 55000:2014 Asset Management (ISO, 2014a). The publication of the first international standard on asset management represents an interesting development in the field of infrastructure asset management. This editorial reflects on the potential impact and importance of the standard to the research and practice communities.

Asset management has seen major advances over the last three decades. Across the globe, there have been advances in standards, models and principles. The evolution of the subject was dependent on individual organisations, researchers, practitioners and professions that supported asset management activity across different countries. The lack of a coordinated global view created two views on asset management, the 'top down' and 'bottom up' approach. The 'top down' approach was the management of assets driven and directly aligned to the strategic objectives of the organisation. The business strategy would lead to the key decisions on assets that would be implemented through the various levels of the organisation. The 'bottom up' approach has its roots in maintenance and reliability. Asset management was seen to be primarily maintenance, reliability and performance. These dimensions influenced asset decision making that was fed up the organisation. The split in asset management philosophy is apparent in the titles of organisations that support the development of asset management. It is not surprising that the international collaborative association for asset management is called the 'Global Forum on Maintenance and Asset Management' (GFMAM 2014a, 2014b). The publication of ISO 55000:2014 represents an impressive collaborative effort among a variety of organisations and interests in 25 countries.

This editorial does not envisage a complete review of ISO 55000:2014, but a quick overview. In its introduction, the standard defines itself as follows:

'This international standard specifies the requirements for the establishment, implementation, maintenance, and improvement of a management system for asset management'.

The standard specifies the requirements for an asset management system with an organisation. It is primarily concerned with physical assets, but it may have application to other assets. The standard is a management system for physical asset management.
The standard has three key documents:

- ISO 55000:2014 Asset Management. Overview, principles and terminology. This document provides an overview of asset management and the standard terms and definitions.

- ISO 55001:2014 Asset Management. Management system requirements. This document is the main standard, specifying the requirements for the management system for asset management (ISO, 2014b).

- ISO 55002:2014 Asset Management. Guidelines for the application of ISO 55001. This document provides advice on how to interpret and implement the standard (ISO, 2014c).

These documents underpin the standard ISO approach. The ISO organisation follows a prescribed approach for management systems such as quality assurance (ISO 9000) and environmental management (ISO 14000). ISO 55000:2014 follows the same managerial system philosophy. The standard is relatively self-contained in terms of the broader principles and components of asset management but makes reference to standards from a variety of support subject areas such as data, risk, quality, reliability, environmental, maintenance, obsolescence and project management. The standard draws on these associated areas to support its approach. The standard sets out to provide guidance for those involved in the establishment, implementation, maintenance, delivery, support service and improvement of asset management systems. The guidance is generic and not sector specific, but technical understanding may be required when dealing with specific asset types and systems.

ISO 55000:2014 is relatively new, but we can reflect on some of the immediate benefits from its creation. A single internationally recognised standard now exists in the asset management community. It brings clarity to terms and definitions within the field. The standard also offers a benchmark of the components of good asset management practice. The standard was produced as a result of an international collaboration, and this should help strengthen the international asset management community, understanding of the subject area and knowledge development.

A major development in the standard is the new language associated with the definition of asset management that reflects assets' contributions to value. There is a shift in the definition toward the view that an asset is something that has potential or actual value 
Infrastructure Asset Management

Volume 1 Issue 2
Editorial - Is ISO 55000:2014 the new

dawn in asset management?

Moodley for the organisation. Asset management according to the standard is a series of coordinated activities that an organisation uses to realise value from assets in the delivery of its goals. Assets exist to provide value for the organisation and its stakeholders. The focus on value allows the standard to align more closely to transparency and financial disclosure requirements. The focus on value creates a closer relationship between technical asset performance, technical reporting and financial reporting. This approach also allows the performance-risk-cost paradigm to be more transparent.

Are there any challenges for the implementation of ISO 55000: 2014 despite its infancy? An immediate concern would be the costs associated with implementation. There are costs associated with the implementation of any new system. It is likely that organisations that run effective or mature asset management systems will not find the transition to a new standard as costly. The process of accreditation will also have associated costs. There will be organisation costs associated with the potential changes needed for integration of roles and teams to meet the requirements of the standard. Changes will need to create a stronger link between financial and technical reporting, and there is likely to be a need for a revised analysis of asset performance data. To counter these increased costs, there would be efficiencies that emerge and offer higher returns.

A healthy scepticism exists for ISO audit systems and challenges the assumptions that they improve performance. A major criticism is the view that the implementation of auditable management systems has focused on the audit, documentation and conformity rather than on continuous improvement and innovation. ISO 55000:2014 will face this challenge to prove that its implementation is more than a tick box exercise and that its implementation will transform asset management practices within an organisation. The standard follows on from similar ISO systems and presents a very generic asset management perspective and lacks a view on best practice. To counter some of these challenges, it is envisaged that the ISO auditors/assessors will have an asset management competency. They will have to be competent to examine the management system from a generic as well as a practice-based asset management competency. The competency needs are extended to the comprehension of asset management as a set of integrated technical and financial risks. GFMAM is drawing up an assessor's competency specification for ISO 55000:2014 to ensure that the systemic criticisms are countered. Negative experiences of previous audit systems represent a significant challenge for the adoption of the standard. It has to be seen to be adding value.

At this early stage, it is difficult to speculate the extent to which ISO 55000 will be adopted by the policy and regulatory environment. Most large-scale physical infrastructures operate within regulated environments. In most cases, the statutory requirements associated with the asset take priority. There will be significant uptake of the standard if regulators see the benefits of moving infrastructure owners and operators to adopt ISO 55000:2014. The audit capability of the standard is an attraction for regulators, but this has to be balanced against benefits and value for money for asset owners and operators. The standard is more likely to be adopted by privately funded public infrastructure owners and large-scale private sector asset operators and owners. The link between value and financial performance will be of particular interest to stakeholders in these organisations. The standard also helps with the understanding of the relationship between asset performance and asset value and, ultimately, profitability. The adoption of the standard is dependent on the pressure from stakeholders and their perception of its added value.

What are the implications of the ISO 55000:2014 for the body of knowledge in asset management? The standard does not revolutionise asset management knowledge or understanding. It provides a set of consistent definitions and a benchmark for the components of an asset management system. It is cautionary from a knowledge development perspective to never allow any system or set of definitions to remain unchallenged. The standard is not a knowledge outcome in itself. It does point to the interdisciplinary nature of asset management and references 25 additional subject areas that need understanding along with the standard. The competency framework and landscape document suggested by GFMAM to support the standard also presents research challenges for both individuals and organisations. The emergence of the standard will hopefully enhance knowledge development by stimulating research and best-practice development across the range of subjects associated with asset management.

ISO 55000:2014 is not the panacea for asset management practice. It offers a route map on the journey to better asset management. Its long-term influence cannot be judged this early in its creation. The excitement created by its introduction will hopefully help stimulate better practice and new research initiatives into infrastructure asset management.

\section{REFERENCES}

GFMAM (Global Forum on Maintenance and Asset Management) (2014a) The Asset Management Landscape, 2nd edn. See http://www.gfmam.org/files/ ISBN978_0_9871799_2_0_GFMAMLandscape_ SecondEdition_English.pdf (accessed 14/05/2014).

GFMAM (2014b) Competency Specification for an ISO 55001 Asset Management System Auditor/Assessor. See http://www.gfmam. org/files/ISBN978_0_9871799_3_7_GFMAM_ISO55001_ Auditor_Assessor_Specification.pdf (accessed 14/05/2014). ISO (International Organization for Standardization) (2014a) 55000:2014 Asset Management - Overview, principles and terminology. ISO, Geneva, Switzerland.

ISO (2014b) 55001:2014 Asset Management - Management systems - requirements. ISO, Geneva, Switzerland.

ISO (2014c) 55002:2014 Asset Management - Guidelines for the application of ISO 55001. ISO, Geneva, Switzerland.

\section{WHAT DO YOU THINK?}

To discuss this paper, please submit up to 500 words to the editor at journals@ice.org.uk. Your contribution will be forwarded to the author(s) for a reply and, if considered appropriate by the editorial panel, will be published as a discussion in a future issue of the journal. 